\title{
Modeling Of Multi-Objective Process Plan, Its Optimization using Linear Modeling Technique
}

\author{
Umer Asgher ${ }^{1}$, Riaz Ahmad ${ }^{2}$, Aamer Ahmad Baqai ${ }^{3}$ \\ ${ }^{1,2,3}$ National University of Sciences and Technology \\ Islamabad, Pakistan \\ 1'umer_asgher2000@yahoo.com, ${ }^{2}$ riazcae@yahoo.com, ${ }^{3}$ aamer.baqai@ceme.nust.edu.pk
}

Received: April 28, 2019. Revised: June 22, 2021. Accepted: October 21, 2021. Published: November 24, 2021.

\begin{abstract}
The Process planning is the procedure to opt for and schedule manufacturing procedure so as to attain one or more organizational goals and suit with a set of constraints. More specifically a Process planning in the reconfigurable manufacturing setup engages a sequence of all activities from raw material storage into the finished manufactured yield. In the current study a manufacturing setup of automotive industry is discussed. At the outset of papers, a basic process plan is modeled that includes design requirements after that it is mathematically modeled. Mathematically modeled process plan is then optimized in order to find optimal solution. Research then search the potential of linear programming optimization technique in handling optimization of process plan.
\end{abstract}

Keywords-Process planning; linear modeling; linear optimization; Linear programming algorithms, manufacturing framework.

\section{INTRODUCTION}

The Productions are the building of new things either physical or intangible. Production is the primarily a major human activity contained by present manufacturing society and is analysed as a cultural motion. Industrialized Process varies in space and time. Process planning is a link between engineering drawings and the final part manufacturing. Process planning in the reconfigurable manufacturing setup involves a series of all activates as of a raw material into the final manufactured product [1].

In engineering design problems often goal is to maximize or minimize certain parameter or a variable. Likewise optimization algorithms frequently used in design problems to minimize overall weight, cost, time or maximize the quality. This work focuses on the study of an optimization approach which will optimize the processing time in the manufacturing setup. Time is a variable in this study and time is the vital entity to be optimized [2][8]. The under analysis artifact whose process plan is developed in our research is the side door plate of armored security transport vehicle (AST). Side plate is prepared from aluminum (AL). Armored security transport vehicle (AST) factory is one of the major factories that work under umbrella of public private partnership in Pakistan. The well-known armored security transport vehicle is a family of vehicles that are manufactured in this AST factory is by means of CNC machines, CAM systems, MIG and TIG aluminum welding, chemical cleaning, coating and panting and radiographic inspection. The factory main products ranging from major sophisticated security trucks to armored security transport vehicle (AST). The factory presently produces several variants of the indigenous wheeled internal security vehicle. It is built with both aluminum and steel bodies that protect occupants from small arms fire. The derivation is based on those of commercial vehicles. The AST series can be fitted with manned and remote controlled gun turrets on the roof.

\section{LITERATURE REVIEW}

All manufactured goods have various scheduling linked by it. In industrialized organizations, it is theoretically known as process planning. First task in industrialized organization, once they get fresh drawings, is to carry out the process planning. This mission, as accomplished, usually direct mutually the association of desirable resources plus the genuine manufacture of the manufactured goods [3]. In today's sophisticated manufacturing, the concept of manufacturing is taken from its basic definition; to build stuff by hand. Though the current has fairly widen: 'Manufacturing' is the transfer of design to a complete product', and production have narrow span, explicitly the physical work of building the product .1983 International Conference on Production. Research defines manufacturing as "sequence of interconnected activities \& operation connecting the design, materials, manufacturing, quality control, management and advertising of products of the industries". This definition includes the inextricable linking of design into the manufacturing system. 'Manufacturing' should be recognized as a series of productive activities of design, procurement, planning, production, marketing, distribution, inventory, sales, and management [4].

There are many radical steps in process planning. Steps entail a cautious revise of each part and formative the manufacturing processes required to manufacture it into the outline revealed in the design's diagram. Tasks are followed by sequence so as they pursue and organize in a way in which they would be executed. This sequencing of activities is vital for motive that the cataloging just scheduled recognized processes and activities essential to formulate each part 
component, although didn't assemble in the order or succession, where they actually take place during the fabrication process. It is vital that the machines and tooling requisite to process each part component, plus the time for the entire process is allocated. Unit of time ought to be in minutes and all machines; tools have to be obviously allocated and recognized [5][9]. The development charts also help in making and analyzing the route sheets. Route sheet is a process training document that are expressively involved to parts, components lots as they make their way in the order throughout processing. They hold directions, stating and allocating work center to the parts and which comes after that, parts waiting is also accomplished. The process chart constructs the chore arrangement of the route sheet. The route sheet does not enclose all the additional details akin to processing time. The chart assists to disclose needless and time waste practices. Process planning engross and formative the mainly suitable manufacturing process and the arrangement in which they ought to be execute to make product specified by design engineering. Each process plan is developed to optimize some defined criteria. Likewise other engineering designs and operations of a process plant have optimal rate of production criteria, minimize cost or maximize the component's life criteria. These criteria, choices available to meet the goals and requirements. The choices are known as optimization variables [7].

Process Optimization in typical Industrial Problems are solved by usually Mathematical Programming and Software like Mathematical Basis for Optimization Lagrange Multipliers ,the Simplex Algorithm , Generalized Reduced Gradient Algorithm ,On-Line Optimization ,Mixed Integer Programming, mixed integer nonlinear programming problem and Global optimization. The method we will employ here is the linear programming (LP) method to solve over mathematical equations and get the optimal results. The reason for using LP here is because all the constraints as well as the objective function is linear and it is the fastest method to reach the optimal solution [6].

\section{MANUFACTURING PRODUCTION LINE, RESEARCH PROCESS}

Fundamental purpose of process planning in AST side plate development procedure is to itinerary and the order all phases beginning primary stage of raw material to the final stage of refined product. Comprehensive planning of the entire the operation is determined and decisive at first point. The two processes run in parallel that is the side plate and side door manufacturing. The work flow pattern of side plate is the combination of processes and the prototype pattern [8]. The process in the research is multi objective in terms of cost, time and quality.

\section{A. Stage-I "Processes of Side Plate" (Raw material storage space to the Surface treatment of side plate)}

First of all the Raw material are stock up in form of 10 plates piled up and denoted by $\mathrm{Y} 1$ as the time to store. The Aluminum (Al) plates $\mathrm{s}$ are send from storage to the two dimensional savage saw intended for rough cutting of plates. The plates are cut to size. The total time consumed is 120 minutes(mins). This is the operation time and is denoted by
Y2. Delay between activities is Y3. To inspect and ensure right size and quality excellence the plates are send to quality control-QC and are denoted by Y4. The time spent is 20 minutes. Aluminum plates are machined in accordance with PRO- E software design, the Pro E provides the suppleness to specify the trivial diagram information in design. The notation this activity is Y6 as Y5 is the transfer time. CNC machining of side plates carried out in 2 different phases: The time consumed in the first phase is 200 minutes (Y6). The time consumed in the second phase is 100 minutes and is denoted by $\mathrm{Y} 8$ as $\mathrm{Y} 7$ is the transfer time. The third QC consumes the time of 50 minutes. The notation is Y9. Al plates following QC-II are transferred (Y10) to the semi automatic drilling. These human operators have to drill on the seats of side plates, the places that were particularly specific with spot drill in previous process. The time consumed on this activity is 120 minutes. The notation used for this activity is Y11. The third phase of the quality control following semi auto drilling; to ensure right size and excellence. The time for this activity is 20 minutes. The notation for this activity is Y13 as Y12 is the delay time. The aluminum plates are moved (Y14) to 400 ton hydraulic press, the time consumed on this activity is 30 minutes having notation of Y15. A manual process where operators are engaged to debar the aluminum plate. It is performed to eradicate additional hangings and sharp edges; the finishing is done with micro files and micro glass-paper. The time spend is 30 minutes. The notation is Y17 as Y16 is transfer time. The surface treatment is the main effectual phase in all process planning; here aluminum plates endure chemical processes to ensure the grains harden as well as corrosion protection. There are in total two phases and each phase has 4 stages. Phase I process is applied on side plate before welding and phase - II after welding. This phase includes activities Y19 as Y18 is again transfer time, for 15 minute at temperature of $140 \mathrm{~F}-160$ F. Then a tank holds cold water for 2 minutes. This second stage takes 15 minutes. Al plates are transported to the tank that holds phosphoric acid and $\mathrm{H}_{2} \mathrm{O}$. The plate remains there for 10 minutes. Al Plates are brought to tank 4 that contains Sulphoric acid 10 minute. The fourth stage of the quality control to inspected and scrutinizes the wholeness of the surface treatment. The time is 20 minutes activity is Y21 as Y20 is the delay time.

\section{B. Stage-II "Process of Side Door" (Plasma Cutting to the Semiautomatic Welding)}

Plasma cutting is a technique to cut steel in 480 minutes. The notation used for this activity is Y23D, D shows activity of side door and Y22 is the delay time. Then Side door is examined to make sure the right measurement in 50 minutes. It is denoted by $\mathrm{Y} 25 \mathrm{D}$ Side door is transferred to semi automatic welding post in 180 minute. The notation is Y27D. This is sixth stage of quality control is done there after in 20 minutes. The notation is Y29D.

\section{Stage-III "Process of Side Plate parallel with side door"}

These are the process that runs in parallel. Aluminum plate is welded with $3 \mathrm{Al}$ firings pots clampers in 230 minutes. The notation used for this activity is Y24S because it runs parallel with previous side door activities therefore their sequence is in between. The side Plate is then examined to make sure the 
accurate welding of the door. Time consumed on this activity is 30 minutes. This action is Y26S. The Aluminum side plate is transported (Y27S) to surface treatment stand. Side plate is once more process throughout previous 4 stages of the Phase I of the surface treatment. Phase I contains by some new stage treatments as discussed under. The notation used for this activity is Y28S and the total time consumed at all the stages is 40 minutes. Phase I contains by some new stage treatments as discussed under. The notation used for this activity is Y30S and the total time consumed at all the stages is 45 minutes.

\section{Stage-IV “Process of Side Door's next stage of surface treatment"}

The side door is passed throughout subsequent stages. The notation used for this action is Y30D, D shows it's the door's operation. The notations $\mathrm{S}$ and $\mathrm{D}$ are used in parallel processes. These stages are Tank 1 for 15 mins at temperature of $140 \mathrm{~F}$ to160 F. Then at Tank 2 water rinse that contains cold water for 2 minutes time. Total time is 15 minutes. Then Tank 3deoxidine Steel door is transported tank 3 that contains phosphoric acid for 10 minutes at of $140 \mathrm{~F}$ to $160 \mathrm{~F}$. Tank 4 Deoxidizer has Sulphuric acid, ferric acid for 10 minutes time at room temperature. Tank 8 of Phosphating. The door is transported here and dipped into the solution for 10 minutes. Then ninth stage of quality control. The parts examined to make sure the good quality of treatment in 30 minutes. The notation used for this activity is Y32S. Few of the variables Ys are missing in processes because either they are the transfer times or delay times also known as non value times or controlled times.

\section{E. Stage-V “Assembly Stage of Side plate and Side door"}

The side door then is fixed with Al side plate with the aid of the clamps. The complete process consumes 280 minutes. The notation used for this activity is Y34. After the Al side plate and side door assembly, the inspection checks are done to make sure the wholeness of the assembly process in 30 mins. The notation used for this activity is Y35. Painting is carried out using compress pain gun. The complete painting process is finished in 480 minutes denoted by Y38. Finally here at quality assurance stage all the quality checks that were examined in the entire QCs are ensured as per user specifications. Quality assurance process takes in total 480 mins. The notation used for this activity is $\mathrm{Y} 40$.

\section{Mathematical Modeling OF THE PROCESS PLAN}

The process planning activities that we are conferring is modeled mathematically using time as a variable and defines the process time with the variable $\mathrm{Y}$ (name). Then the controlled time and uncontrolled variable times will be used in modeling. The mathematical model is formed in conditions of processing time of each operational activity (uncontrolled) and the time concerned in the non-valued or non operational activities (controlled). In the above discussion all the notations of activities formed by the time variable $\mathrm{Y}$ in from $\mathrm{Y} 1$ to the Y40 then all the controlled times are combined so that the activities are reduced from Y1 to Y32. All the modeling parameters and postulations are as follow, from the very start manufacturing of side plate and side door runs in analogous. There uncontrolled time linked with operational activities and controlled times such as delays and waiting time and transfer time. The controlled variables can be altered and are in control so we can combine these variables just like in case of $\mathrm{Y} 1$ we combine all the transfer times having the same values as of Y1 and write it as $8 \mathrm{Y} 1$. The uncontrolled processes times like machining time is set and is uncontrolled just like Y2 where the cutting time on a machine cannot be altered and cannot be combined with other operational times like $\mathrm{Y} 4$ which is the operational time of CNC process.

\section{OBJECTIVE FUNTION AND PROGRAMMING}

Our aim is to minimize the process time while remaining in the constrains. So the problem comes out to be constrained optimization. Objective function is as under in (1):-

$$
\text { Minimize } \mathrm{f}=\sum_{n=1}^{32} Y \cdot b(n)
$$

Where $\mathrm{Y}$ is the variable time

$\mathrm{b}(\mathrm{n})$ is the coefficients which are constants.

Below are the 32 Constraints (equality, inequality constraints and also upper and lower bounds). Fig. 2 and Fig. 3 show the Matlab program and the code written to solve the objective function and the constraints.

\begin{tabular}{|c|c|c|c|}
\hline $\begin{array}{l}\sum_{m=1}^{32} Y \cdot b(m) \leq \\
\sum_{m=3}^{32} Y \cdot b(m) \leq\end{array}$ & $\begin{array}{l}\leq 2350.00, \sum_{m=2}^{32} Y . b(m) \\
\leq 2170.00, \quad \sum_{m=4}^{32} Y \cdot b(m)\end{array}$ & $\begin{array}{l}\leq \\
\leq\end{array}$ & $\begin{array}{l}2270.00 \\
2150.00\end{array}$ \\
\hline$\sum_{\mathrm{m}=5}^{32} \mathrm{Y} \cdot \mathrm{b}(\mathrm{m}) \leq$ & $\leq 2140.00, \quad \sum_{\mathrm{m}=6}^{32} \mathrm{Y} \cdot \mathrm{b}(\mathrm{m})$ & $\leq$ & 2135.00 \\
\hline$\sum_{\mathrm{m}=7}^{32} \mathrm{Y} \cdot \mathrm{b}(\mathrm{m}) \leq$ & $\leq 1985.00, \sum_{\mathrm{m}=8}^{32} \mathrm{Y} \cdot \mathrm{b}(\mathrm{m})$ & $\leq$ & 1945.00 \\
\hline$\sum_{\mathrm{m}=9}^{32} \mathrm{Y} \cdot \mathrm{b}(\mathrm{m}) \leq$ & $\leq 1865.00, \sum_{\mathrm{m}=10}^{32} \mathrm{Y} \cdot \mathrm{b}(\mathrm{m})$ & $\leq$ & 1835.00 \\
\hline$\sum_{\mathrm{m}=11}^{32} \mathrm{Y} \cdot \mathrm{b}(\mathrm{m}) \leq$ & $\leq 1735.00, \sum_{\mathrm{m}=12}^{32} \mathrm{Y} \cdot \mathrm{b}(\mathrm{m})$ & $\leq$ & 1715.00 \\
\hline$\sum_{\mathrm{m}=13}^{32} \mathrm{Y} \cdot \mathrm{b}(\mathrm{m}) \leq$ & $\leq 1705.00, \sum_{\mathrm{m}=14}^{32} \mathrm{Y} \cdot \mathrm{b}(\mathrm{m})$ & $\leq$ & 1685.00 \\
\hline$\sum_{\mathrm{m}=15}^{32} \mathrm{Y} \cdot \mathrm{b}(\mathrm{m}) \leq$ & $\leq 1670.00, \sum_{\mathrm{m}=16}^{32} \mathrm{Y} \cdot \mathrm{b}(\mathrm{m})$ & $\leq$ & 1640.00 \\
\hline$\sum_{\mathrm{m}=17}^{32} \mathrm{Y} \cdot \mathrm{b}(\mathrm{m}) \leq$ & $\leq 1580.00, \sum_{\mathrm{m}=18}^{32} \mathrm{Y} \cdot \mathrm{b}(\mathrm{m})$ & $\leq$ & 1570.00 \\
\hline$\sum_{\mathrm{m}=19}^{32} \mathrm{Y} \cdot \mathrm{b}(\mathrm{m}) \leq$ & $\leq 1170.00, \sum_{\mathrm{m}=20}^{32} \mathrm{Y} \cdot \mathrm{b}(\mathrm{m})$ & $\leq$ & 970.00 \\
\hline$\sum_{\mathrm{k}=21}^{32} \mathrm{Y} . \mathrm{b}(\mathrm{k})$ & $\leq 940.00, \quad \sum_{\mathrm{m}=22}^{32} \mathrm{Y} \cdot \mathrm{b}(\mathrm{m})$ & $\leq$ & 925.00 \\
\hline$\sum_{\mathrm{m}=23}^{32} \mathrm{Y} \cdot \mathrm{b}(\mathrm{m}) \leq$ & $\leq 825.00, \quad \sum_{\mathrm{m}=24}^{32} \mathrm{Y} \cdot \mathrm{b}(\mathrm{m})$ & $\leq$ & 795.00 \\
\hline$\sum_{\mathrm{m}=25}^{32} \mathrm{Y} \cdot \mathrm{b}(\mathrm{m}) \leq$ & $\leq 785.00, \quad \sum_{\mathrm{m}=26}^{32} \mathrm{Y} \cdot \mathrm{b}(\mathrm{m})$ & $\leq$ & 775.00 \\
\hline$\sum_{\mathrm{m}=27}^{32} \mathrm{Y} \cdot \mathrm{b}(\mathrm{m}) \leq$ & $\leq 745.00, \quad \sum_{\mathrm{m}=28}^{32} \mathrm{Y} . \mathrm{b}(\mathrm{m})$ & $\leq$ & 730.00 \\
\hline$\sum_{\mathrm{m}=29}^{32} \mathrm{Y} \cdot \mathrm{b}(\mathrm{m}) \leq$ & $\leq 715.00, \quad \sum_{\mathrm{m}=30}^{32} \mathrm{Y} \cdot \mathrm{b}(\mathrm{m})$ & $\leq$ & 515.00 \\
\hline$\sum_{\mathrm{m}=31}^{32} \mathrm{Y} \cdot \mathrm{b}(\mathrm{m}) \leq$ & $\leq 500.00, \quad \sum_{\mathrm{m}=32}^{32} \mathrm{Y} . \mathrm{b}(\mathrm{m})$ & $\leq$ & 100.00 \\
\hline \multicolumn{4}{|c|}{ 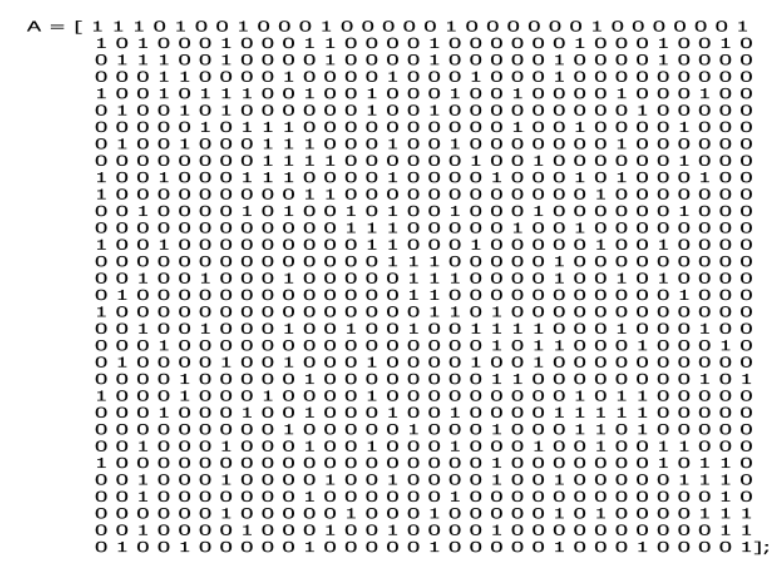 } \\
\hline
\end{tabular}

Fig 2. Constraint matrix in Matlab 


\section{$B=120 ; 30 ; 170 ; 30 ; 320 ; 20 ; 450$ 200 ; 240; 230 ; 100; $200 ; 110 ; 60$ \\ $250 ; 650 ; 200 ; 700 ; 450 ; 280$; \\ $370 ; 70 ; 100 ; 150 ; 65 ; 250 ; 470$ \\ $700 ; 480 ; 670 ; 650 ; 1501$; \\ [X,FVAL,EXITFLAG,OUTPUT,LAMB DA] =}

LINPROG (F,A,B,[],[],[]);

\section{Fig 3. Programs in Matlab}

After applying the matlab program on the objective funtion and the constraints we get the optimized time. Since the funtion as well as the contraints are linear so applied LP method i.e.,Gussian method to slove this linear problem. The values in table I show the comparission of actual manufacuring time of the different process and the optimized time after solving the objective funtion. The fig. 4 shows the comparrions in graphical form and shows a major improvement after applying the LP optimization specially at X16, X22, X29 and X31, where the graph shows the highest difference peaks.

Table I-Variable, actual time and the LP optimized time

\begin{tabular}{|c|c|c|}
\hline VARIABLES & $\begin{array}{c}\text { ACTUAL } \\
\text { TIME }\end{array}$ & $\begin{array}{l}\text { OPTIMIZED TIME } \\
\text { MATLAB RESULTS }\end{array}$ \\
\hline $\mathrm{X} 1$ & 120 & 80 \\
\hline $\mathrm{X} 2$ & 120 & 100 \\
\hline $\mathrm{x} 3$ & 40 & 20 \\
\hline $\mathrm{X} 4$ & 20 & 10 \\
\hline X5 & 10 & 5 \\
\hline X6 & 200 & 150 \\
\hline $\mathrm{X} 7$ & 80 & 40 \\
\hline $\mathrm{x} 8$ & 100 & 80 \\
\hline x9 & 50 & 30 \\
\hline X10 & 120 & 100 \\
\hline X11 & 40 & 20 \\
\hline $\mathrm{X} 12$ & 20 & 10 \\
\hline X13 & 30 & 20 \\
\hline X14 & 30 & 15 \\
\hline X15 & 50 & 30 \\
\hline X16 & 180 & 60 \\
\hline X17 & 20 & 10 \\
\hline X18 & 480 & 400 \\
\hline
\end{tabular}

\begin{tabular}{|c|c|c|}
\hline X19 & 230 & 200 \\
\hline X20 & 50 & 30 \\
\hline X21 & 30 & 15 \\
\hline X22 & 180 & 100 \\
\hline $\mathrm{X} 23$ & 50 & 30 \\
\hline X24 & 20 & 10 \\
\hline X25 & 15 & 10 \\
\hline X26 & 60 & 30 \\
\hline X27 & 30 & 15 \\
\hline X28 & 30 & 15 \\
\hline X29 & 280 & 200 \\
\hline X30 & 30 & 15 \\
\hline X31 & 480 & 400 \\
\hline X32 & 200 & 100 \\
\hline & 3395 & 2350 \\
\hline TOTAL & & \\
\hline
\end{tabular}

\section{Avtual Vs Optmized time}

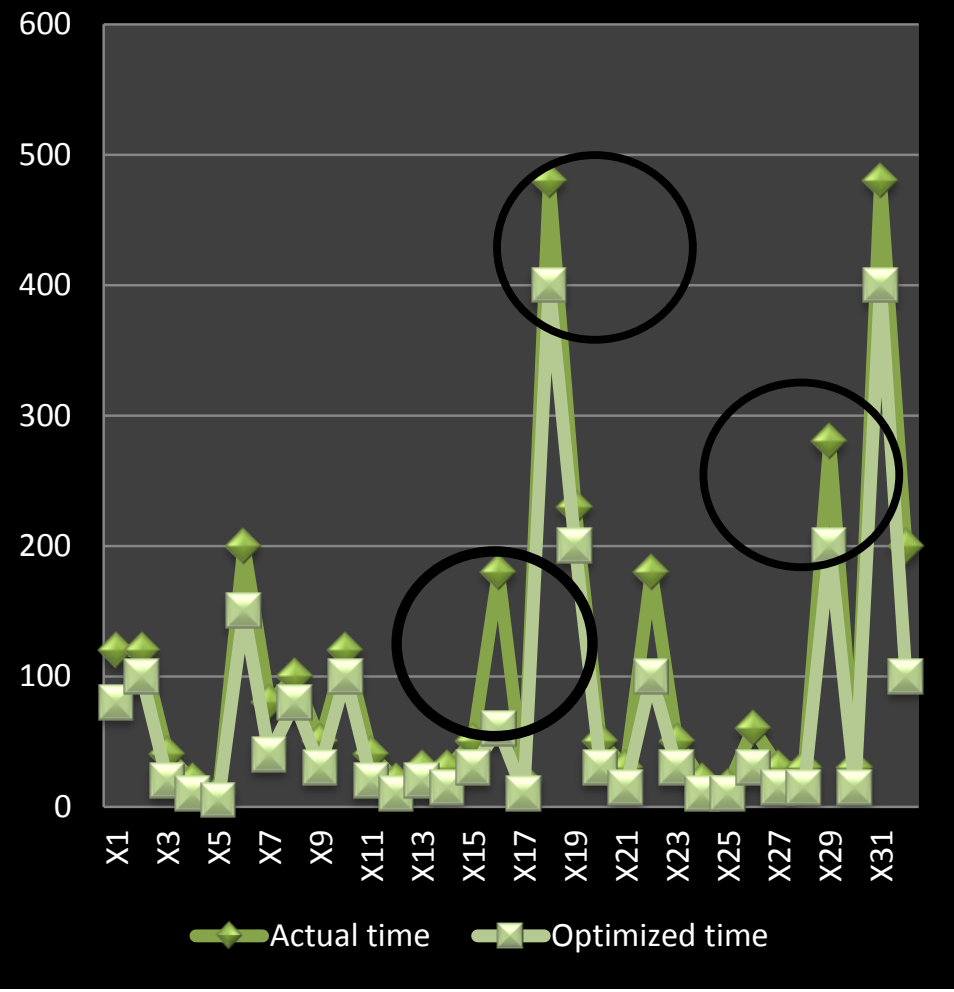

Fig.4 Comparrision between actime and the linear optimed time 


\section{CONCLUSIONS-DEDUCTIONS FROM} OPTIMIZATION OF LINEAR PROGRAMMING

Manufacturing process plan is developed on the basis of actual production flow and considering all the time constraints. The objective function is multi objective as time and cost are the optimization parameters. In our research we consider time as optimization parameter. In order to optimize the time we need to have an objective function, so the objective function and the constraints are modeled first, the objection function is solved to get the optimized manufacturing times in the process plan. The results are obtained from Liner Optimization using Matlab program. The method we used here is simplex (Gaussian) to compute the results considering all the constraints. It is obvious from the table I and the fig. 4 that there is a considerable improvement in case the results from Linear Programming Optimization and the optimization has dragged down the actual manufacturing time from 3395 minutes to 2350 minutes.

\section{REFERENCES}

[1] K. Hitomi Viva, Manufacturing Systems Engineering, 2nd ed, India: Viva Books Pvt Ltd.

[2] Badea Lepadatescu, Luminita Popa, Constantin Buzatu, "Studies and Researches regarding a Mathematical Model of Superfinishing Manufacturing Process," Proceedings of the 3rd European Conference of Mechanical Engineering (ECME' 12), WSEAS Press, pp 151-157.

[3] A. Nedelcu, L. Sangeorzan, A.-E. Dumitrascu, G. Oancea "Optimization of the Process Planning by Decision-Making Laws within Manufacturing Flexible Systems," Proceedings of the 9th WSEAS International Conference on simulation, modelling and optimization (SMO '09), pp 147-151.

[4] Petrianu Cristian, Ință Marinela, Manolea Daniel, Muntean Achim, "Modeling and Experimental Validation of $\mathrm{CO} 2$ Laser Cutting Process for Stainless Steel," Proceedings of the 5th WSEAS International Conference on Manufacturing Engineering, Quality and Production Systems (MEQAPS '12), pp 37-40.

[5] Diego Arbelaez, Modeling and Simulation of Granular Flows for Industrial Applications ,USA: ProQuest, 2008, University of California, Berkeley.

[6] J.M. Usher and K.J. Fernandes, "Dynamic process planning - the static phase,” Journal of Materials Processing Technology, pp. 53-58,1996.

[7] Rehg, James A. \& Kraebber, Henry W. Computer-Integrated Manufacturing, 3rd ed, Prentice-Hall: 2005, Englewood Cliffs, N.J.

[8] M. Asghar Bhatti, Practical Optimization Methods with Mathematics Applications, N.Y : Springer-Verlag, 2000.

[9] Jose P. Garcia-Sabater, Julien Maheut, Julio J. Garcia-Sabater "A twostage Sequential Planning Scheme for Integrated Operations planning and scheduling system using MILP: the case of an engine assembler," Flexible Services and Manufacturing Journal, vol. 24, Issue 2, pp 171209, June 2012.

\section{Creative Commons Attribution License 4.0 (Attribution 4.0 International, CC BY 4.0)}

This article is published under the terms of the Creative Commons Attribution License 4.0 https://creativecommons.org/licenses/by/4.0/deed.en US 